\title{
Knowledge and Practices of Post Cesarean Section Mothers Towards Self-Care After Delivery at Mbarara Regional Referral Hospital.
}

\author{
Solomon Atuhaire ${ }^{a}$ \\ a Department of Nursing, Mbarara University of Science and Technology
}

\begin{abstract}
\end{abstract}

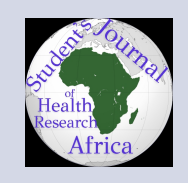

Background: ${ }^{a}$

It is recommended to all mothers to undergo post-cesarean section self-care after delivery up to six weeks. However, many mothers return to Mbarara Regional Referral Hospital as a result of getting some complications related to cesarean section. The reasons why these mothers develop these complications are not clear and possible other practices performed by delivered mothers to solve their post-delivery challenges are not yet documented.

Methods:

The design of this study was a descriptive cross-sectional study design and a semi-structured questionnaire was used to collect quantitative data from the participants. Data were collected from 150 mothers admitted to the Maternity ward of Mbarara Regional Referral Hospital who formed the inclusion criteria and accepted to participate in the study. Data was captured using Microsoft excel and analyzed using Statistical Package for social sciences (SPSS).

Results:

The response rate in this study was $100 \%$. The knowledge of post-cesarean section self-care among postpartum women at MRRH in Mbarara was poor as the majority of the participants 90(60\%) reported to have never heard about Post Cesarean self-care while only 60 (40\%) reported having ever heard about Post Cesarean self-care and no postpartum woman was fully aware of all the aspects of PCS and only $26 \%$ could talk of more than 2 aspects of the PCS. The findings of the study also revealed that $22 \%$ (33) of the postpartum women don't perform PCS at all. This shows a low practice of PCS among postpartum women.

Conclusion and recommendations:

Generally, in this study, the knowledge of post-cesarean section self-care among postpartum women at MRRH in Mbarara was poor, suggesting that these postpartum women are unaware of the value of this personal health promotion tool.

\footnotetext{
${ }^{a}$ Email: atuheiresolomon61@gmail.com Received: 9th/12/2020 Accepted: 11th/02/2021 Journal of Obstetrics and Gynecology
}

\section{BACKGROUND:}

"Cesarean delivery, also known as C-section, is a major abdominal surgery involving two incisions 
(cuts): one is an incision through the abdominal wall and the second is an incision involving the uterus to deliver the baby." (Harish, 2019).

Harish continues to enlighten us about the most frequent reasons for performing C-sections which include previous cesarean deliveries, lack of labor progression, abnormal position of the fetus, fetal status, and emergencies. The rate of cesarean sections is increasing and this may be attributed to both technological and social changes (Daftary et al., 2011).

The increasing rate of cesarean sections around the world is really "alarming" (Michaeleen, 2018). Since 1990 C-sections have more than tripled from about $6 \%$ of all births to $21 \%$ and there are no signs of slowing down, such rates are due mainly to an increase of elective C-sections. For a woman, an elective $\mathrm{C}$-section can raise the chance of death by at least $60 \%$ and it increases a woman's risk of lifethreatening complications during childbirth such as bleeding, uterine rupture, hysterectomy, and cardiac arrest by about fivefold (Michaeleen, 2018).

$\mathrm{C}$-Section is the most commonly performed surgical procedure in the world and should be a highquality lifesaving technology that allows pregnant women, their offspring, and their support networks to continue to lead healthy, productive lives, an analysis evaluating maternal deaths in the setting of Cesarean Section found that the risk of a woman dying after CS was almost three times the risk of maternal death after vaginal delivery (Harrison et al., 2016).

All women who delivered by CS in 29 African, Asian, Latin American and Middle Eastern countries, $62.5 \%$ experienced a severe maternal outcome, which was significantly different than the $37.5 \%$ of vaginal deliveries where a severe maternal outcome was reported, the results also showed that about twice the percentage of women who had a severe maternal outcome had greater than one prior CS as compared with women who did not, suggesting that tertiary or higher CS are associated with adverse maternal outcomes (Harrison et al., 2016).

The postpartum period is the most neglected period for the provision of quality care and yet most maternal deaths together with morbidities occur in this period (Nankwanga, 2008). Postpartum rehabilitation is essential and should be started the day after the baby is born and continued until the baby is at least six months old (WHO, 2002). Therefore, mothers should be aware of this so that they take it upon themselves to actively care for themselves.

In a study done in England on women who underwent cesarean section at participating hospitals during designated study periods, a total of 394 surgical site infections were identified from 4107 operations, representing a risk of $9.6 \%$. According to Wloch et al., (2012), Three of the women were reported to have developed both an incisional and uterine infection. Eleven percent (44/394) of infections were detected during the initial admission (21) or through readmission to the hospital (23), 55\% (218/394) were detected post-discharge by community midwife or other hospital-based healthcare professional and 34\% (132/394) were reported by the woman and confirmed by the surveillance coordinator. In all, 95\% of the infections were identified after the initial inpatient stay (Wloch et al., 2012)

During the clinical experiences, the investigators found that post-natal exercises were neglected by mothers due to lack of practice, and many mothers at home developed postoperative complications ( Rojamma., 2010). In the United States, a study showed that pregnancy and childbirth overshadowed the postpartum needs of the mother (Hall, 2018).

The nurse normally gave the mother some exercises on discharge without specific instruction, follow up, and medical supervision. Most new mothers returned to normal activities too soon, despite their intuition that their bodies were just not yet ready for quick adjustments (Hall, 2018).

In some developing countries where awareness about the postpartum period, resource availability and people's beliefs differ from developed countries, things are done in completely different ways. In a study done amongst Chinese and Taiwanese women in 2007, it was discovered that women were subjected to a confinement period after birth during the first four weeks postpartum to promote recovery and allow loose bones to return to their previous positions (Dennis, 2007).

Some of these practices during confinement included mainly the prolonged rest, avoiding exerting themselves by climbing stairs, a special diet considered to be nourishing the body, and actions to heighten personal hygiene (Fok et al., 2016)

Also, Chinese and Indian mothers were found to eat special confinement diets, and Chinese mothers to shower less during that period since they believed that this would not only be detrimental 
to their recovery but also compromising the intentions and plans of their caretakers/nannies who restricted them from doing anything (Lim, 2011)

Similarly, Malay mothers greatly used massage to increase circulation and warmth to the mother's body, whilst Indian mothers had their mothers or mothers-in-law as assistant caregivers to help in house chores for them to get enough rest (Kamaria et al., 2015).

In Sub-Saharan Africa, specific policies for postpartum care are weak and there is little evidence of effective postpartum care implementation (Duysburgh et al., 2015; Duysburgh et al., 2016). Postpartum care has remained relatively neglected in many intervention designs to improve maternal health (Djellouli et al., 2017). A study carried out in Nigeria by Adeniyi et al., (2013) about postpartum exercise among 227 Nigerian women showed that $61 \%$ of the women were not aware that they could undertake postpartum rehabilitation in general and/or physical exercise program to enhance health in the postpartum period. As a result, almost half of them (47.8\%) did not engage in any form of physical exercise (Adeniyi et al., 2013). In the same study, it was also highlighted that even those who did exercise, the majority of the prescribed and chose the exercise types by themselves, therefore, the limited possibility for both supervisions and evaluation of the outcome. Brisk walking, cycling, swimming, and weight lifts were the most listed types of exercises mentioned by the participants but the reasons, durations, and frequencies were not thoroughly documented (Adeniyi et al., 2013). This can lead to ineffectiveness of the exercises chosen or it can even exacerbate the condition if done excessively for example weight lifts.

Because of understaffing and workload constraints, this care may not be provided as expected ( Aiken et al., 2018). Because of postnatal ward space, some women may be discharged early to create space for more newly delivered ones (Rudman et al., 2007). This limits the knowledge mothers receive and the understanding of the significance of postpartum self-care as they are being discharged.

Health education components about post-Csection self-care at home may not be adequately handled at the time of discharge. Literature is scanty on how postpartum women care for the operation site at home in Uganda. With the potential complications associated with poor post-cesarean care; this study would like to document the knowl- edge and practices of postpartum women regarding post-C-section self-care.

The postpartum recovery period is usually longer for cesarean births, physiological concern of women after cesarean birth include; fatigue, activity intolerance, and incision problems (Rani et al., 2016)

There are several C-sections done at Mbarara Regional Referral hospital of over 250 C-sections averagely every month and it has been noticed that several mothers who undergo the operations have issues on the operation site which include wound infection, bleeding at the site, and burst abdomen ( HMIS 031 and 054, MRRH records 2019).

There is increased mortality and morbidity of mothers who have undergone Cesarean section at Mbarara RRH. According to (Ngonzi et al., 2016) puerperal sepsis was the leading cause of maternal death at Mbarara Regional Referral Hospital.

According to Zawn Villines et al., (2018) women after a successful C-section, many guides suggest that full recovery takes 4 to 6 weeks. Yet every person is different and much research suggests a significantly longer recovery time. He continues to explain methods that can be used to speed up C-section recovery some of which include getting plenty of rest, asking for help, process your emotions, take regular walks, manage pain, watch for signs of infection, fight constipation and get support for breastfeeding.

According to (UDHS, 2016) only $54 \%$ of women age 15-49 receive a postnatal check within two days and $43 \%$ did not have a postnatal check within 41 days of delivery.

During my clinical rotations in Mbarara Regional Referral hospital, I observed postpartum women being re-admitted for Post Cesarean delivery complications. According to Mbarara University of science and technology, department of Obstetrics and gynecology 24-hour operation reports; 312, 247, and 258 Cesarean sections were done in November, October, and September respectively. In the same period, the hospital, according to the inpatient HMIS 054 and the outpatient HMIS 031 received 19,16 , and 14 puerperal sepsis cases in November, October, and September respectively of which 13,11 and 9 cases were $C$-section surgical site infections respectively.

In the same period still, 2 cases of burst abdomen and 3 cases of bleeding from the surgical site were received. 
With the few, I interacted with they told me they usually resume their work be it heavy or light as early as before a week post-operation and some even apply herbs on their surgical site to reduce pain and enhance healing which also could be contributing to their morbidity.

\section{METHODOLOGY \\ Area of Study}

The study was conducted at Mbarara Regional Referral Hospital (MRRH) which is a public hospital located in Mbarara town in Western Uganda. It is approximately $260 \mathrm{~km}$ southwest of Kampala. The hospital currently serves a population of over 4 million people in its catchment area comprising districts of Mbarara, Bushenyi, Buhweju, Ntungamo, Kazo, Kiruhura, Ibanda, Uhweju, Rubirizi, Rwampara, Mitooma and Isingiro (Ministry of Health, 2011). The Hospital also receives patients from Kabale, Masaka, Fort Portal, and neighboring countries like Burundi, Congo, Rwanda, and Tanzania.

MRRH has several wards including the Accident and Emergency ward, the intensive care unit (ICU), surgical, medical, obstetrics, gynecology, and pediatrics wards. The hospital also operates specialized clinics such as maternal and child health, medical outpatient clinic, neurology clinic, renal clinic, eye clinic, physiotherapy outpatient clinic, skin clinic, surgical and orthopedic clinic, cardiology clinic, ear, nose, and throat (ENT) clinic and oncology clinic. In my study, Patients were recruited from the maternity ward.

\section{Study Population}

The study population was postpartum women who have delivered through a Cesarean Section admitted in the maternity ward at Mbarara regional referral Hospital.

\section{Study Design.}

The study was a descriptive cross-sectional study design. The study employed quantitative methods of data collection. This method was used because it's appropriate for studies that take a short duration and those in which data is collected at one point in time.

\section{Inclusion Criteria}

The study included all postpartum women who were delivered through Cesarean Section admitted in the maternity ward at Mbarara Regional Referral Hospital who consented to participate in the study.

\section{Exclusion Criteria}

All Postpartum women who delivered through cesarean section were mentally ill.

\section{Sample Size Determination}

The sample size was estimated by the Yamane formula (1967:886). The sample size was attained within the selected time of the study regarding the researcher's limited time and resources.

$\mathrm{n}=\mathrm{N} \quad$ Where; $\mathrm{n}=$ sample size, $\mathrm{N}=$ population size of postpartum women

$1+N(e) 2$ with Cesarean section being discharged monthly on average,

e $=$ level of error expected which is 0.05

Estimated sample size, $\mathrm{n}=150$ participants, $\mathrm{N}$ was approximated at 250 women who on average have Cesarean Section monthly. For convenience in data collection, a rounded figure of 150 participants was considered.

\section{Sampling Procedure}

The researcher used a homogeneous purposive sampling method of all women with a Cesarean Section until the required sample was reached. The women were approached from within the facility at the time of discharge. This sampling method was chosen because it selects individuals based on their specific knowledge about a phenomenon; to share that knowledge (Steubert \& Carpenter, 2011). This method was also used because the researcher was targeting only postpartum women delivered with Cesarean Section.

\section{Data Collection Tool}

A questionnaire written in English and Runyankore/Rukiga was used and consisted of both open and closed-ended questions requiring information on demography, knowledge, and practice of women about Post Cesarean Section self-care. That in Runyankole/Rukiga catered for those who were not well conversant with English. The tool was adopted and modified based on literature review and guided by the supervisor to fit in the study area.

The questionnaire had a Brief Post cesarean section self-care knowledge questionnaire scale (KQ-10) that used Yes/No and short structured questions. It has mean performance ranges that show the level of knowledge from the respondents according to their mean performance (Carey \& Schroder, 2002). The mean score was determined and graded as low knowledge if the mean score ranged between $0-4$, moderate knowledge if the 
mean score ranged between 5-7, and high knowledge if the mean score ranged between 8-10.

\section{Data Collection Procedure}

The data was collected by the researcher asking questions using a researcher administered semistructured questionnaire. Each questionnaire was coded before administering it to the participants. Once participants accepted to participate in the study, they were asked questions on a questionnaire and it was completed by the researcher. The questionnaire had 20 questions and filling the questionnaire took about 20 minutes for each participant after which the participants were thanked for participating in the study. By the end of the day, the filled questionnaires were kept in a safe place until the required sample size was reached.

\section{Data Analysis}

Data were analyzed using Statistical Package for Social Scientists (SPSS) Version 25.0.0.0 Findings of the study were presented in form of tables, graphs, and pie charts.

\section{Ethical Consideration}

The research proposal was examined carefully by the research supervisor and the nursing department. Approval of the research proposal was attained and the researcher got an introductory letter from the Department of Nursing at MUST. The proposal was submitted to the Hospital director Mbarara regional referral hospital, approval and authority were sought to conduct this study. The study was fully explained to those who met the inclusion criteria and informed consent was obtained from the participants seeking permission before administering the questionnaire to them. Participants were assured that participation is voluntary and that they were free to withdraw at any time they felt like. Codes were used on participants to ensure confidentiality at all times during the study. No names were used on the questionnaire but only codes and the information generated was kept under key and lock only accessible by the researcher.

\section{Quality control}

\section{Reliability of data}

Pretesting of questionnaires was done before the actual exercise of data collection. The study tool was pretested to any postpartum women with Cesarean section at Mayanja memorial hospital and the gaps in the tool were bridged accordingly.
The questionnaire was selected to collect data which was designed to contain all the information to cater to all the objectives of the study. The questionnaire was designed with the help of the research supervisor to make sure that all the necessary information was included.

\section{Dissemination of results}

A copy of the dissertation was presented to the research supervisor, nursing department library, MUST the main library for easy accessibility and reference by other students and researchers, and Mbarara Regional Referral Hospital. Study results were disseminated to the Department of Nursing, faculty of medicine at MUST, and Mbarara Regional Referral Hospital administration. Dissemination of results was also made through the Nursing department.

\section{RESULTS}

\section{Demographic characteristics of study partici- pants}

The parameters used from demographic characteristics in this study included: age, religion, tribe, level of education, and gravida of postpartum women. These are presented in the subsections below:

\section{Age of the participants}

Out of the total sample of participants, the majority; $46.7 \%(n=70)$ were in the age range of 25 years and above, $26.0 \%(n=39)$ were in the age range of $21-24$ years and $27.3 \%(n=41)$ were 20 years and below years as shown in the table below.

\section{Religions of the participants}

As illustrated in the figure below, 59(39.3\%) of the participants were protestants, $47(31.3 \%)$ of the participants were Catholics, 25(16.7\%) of the participants were Muslims and 19(12.7\%) had any other religions.

Figure 1: Religions of the participants

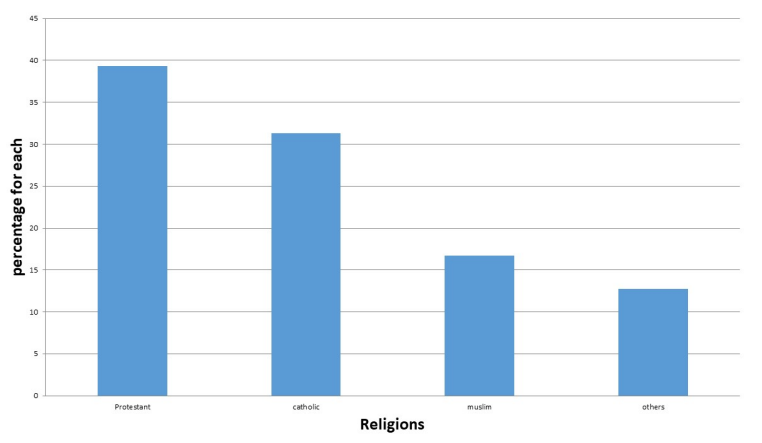


Table 1. The age of the participants

\begin{tabular}{lll}
\hline Age & Frequency & Percent \\
$<20$ & 41 & 27.3 \\
$21-24$ & 39 & 26.0 \\
25 and above & 70 & 46.7 \\
Total & 150 & 100.0 \\
\hline
\end{tabular}

\section{Tribes of the participants}

As seen from the table below, the majority of participants were Banyankole by tribe 110 (73.3\%), followed by Bakiga 23 (15.3\%), Baganda 12 (8.0\%), and other tribes 5 (3.3\%) as seen.

\section{Levels of education}

A bigger percentage of the participants were primary dropouts 74 (49.3\%), secondary 52 (34.7\%), Tertiary $18(12.0 \%)$, and none $6(4.0 \%)$ as shown in the table below.

\section{Number of pregnancies:}

$30 \%$ of the participants $(n=45)$ were prime gravidas, 39.3\% ( $n=59)$ were Gravida $2 s, 14.7 \%(n=22)$ were Gravida $3 \mathrm{~s}$ and $16 \%(n=24)$ were Gravida $4 \mathrm{~s}$ and above.

\section{Knowledge of postpartum women regarding} Post Cesarean self-care

To track the knowledge on Post Cesarean selfcare among postpartum women at MRRH, participants were asked different questions and the results are presented in the figures below.

Figure 2: Percentage of Knowledge

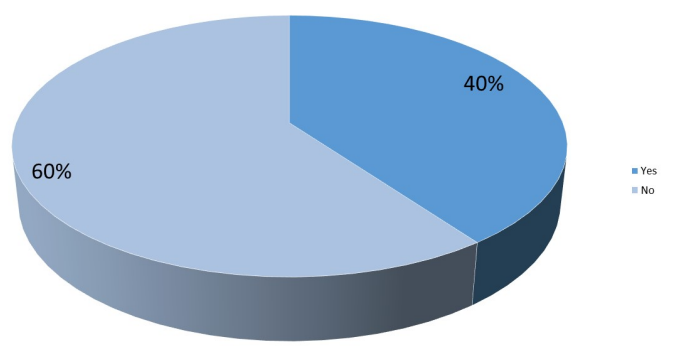

The majority of the participants 90(60\%) reported having never heard about Post Cesarean self-care while only 60 (40\%) reported having ever heard about Post Cesarean self-care as shown in the pie chart above.

Modes through which Participants obtained information about PCS

Those that had ever heard about Post Cesarean self-care, $40 \%(n=24)$ had obtained it from mid- wives, $20 \%(n=12)$ from doctors, $29 \%(n=17)$ from friends/peers, $3 \%(n=2)$ from media and only $8 \%$ $(n=5)$ from other sources as shown in the figure below.

Figure 3: Modes through which participants obtained information about Post Cesarean self-care.
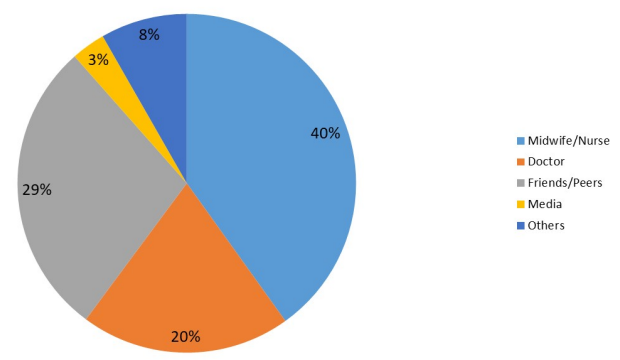

For those that had ever heard about Post Cesarean self-care, the majority had better knowledge about hygiene with a frequency of 43 , followed by the exercise of 32 , then 14 for nutrition, and followed by the others as shown in the graph below.

Figure 4: Knowledge level on Post Cesarean self-care components

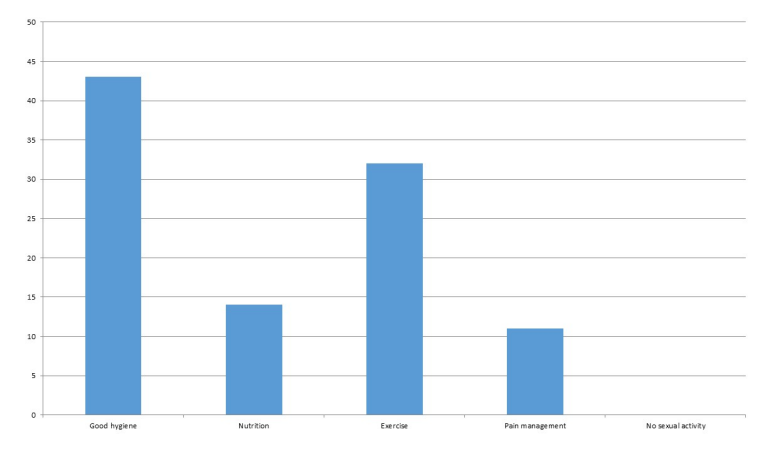

Complications if Post cesarean section self -care isn't practiced

Sepsis was the highest known complication to the participants with a frequency of 116 . Then 
Table 2. Tribes of participants

\begin{tabular}{llll}
\hline \multirow{2}{*}{ Tribe } & & & \\
& & Frequency & Percentage \\
& munyankole & 110 & 73.3 \\
& mukiga & 23 & 15.3 \\
& muganda & 12 & 8.0 \\
others & 5 & 3.3 \\
Total & 150 & 100.0 \\
\hline
\end{tabular}

Table 3. Participants' levels of education

\begin{tabular}{lll}
\hline Level of education & Frequency & Percentage \\
None & 6 & 4.0 \\
primary & 74 & 49.3 \\
secondary & 52 & 34.7 \\
Tertiary & 18 & 12.0 \\
Total & 150 & 100.0 \\
\hline
\end{tabular}

Table 4. Gravidity of post-partum women

\begin{tabular}{lll}
\hline Gravidity & Frequency & Percentages \\
PG & 45 & 30.0 \\
G2 & 59 & 39.3 \\
G3 & 22 & 14.7 \\
Above G3 & 24 & 16.0 \\
Total & 150 & 100.0 \\
\hline
\end{tabular}

Table 5. Table 5: Participants' complications if Post c esarean section self -care isn't practiced.

\begin{tabular}{ll}
\hline Complications if Post Caesarean Self-care isn't Practiced & Frequency \\
Sepsis Bleeding Bursting Pain Death & 11617443029
\end{tabular}

followed by burst abdomen, pain, death, and finally bleeding as shown in the table below

The self-rated level of knowledge of the participants was rated as low, moderate, and high using their mean scores as shown in the graph below

Figure 5: The self-rated level of knowledge

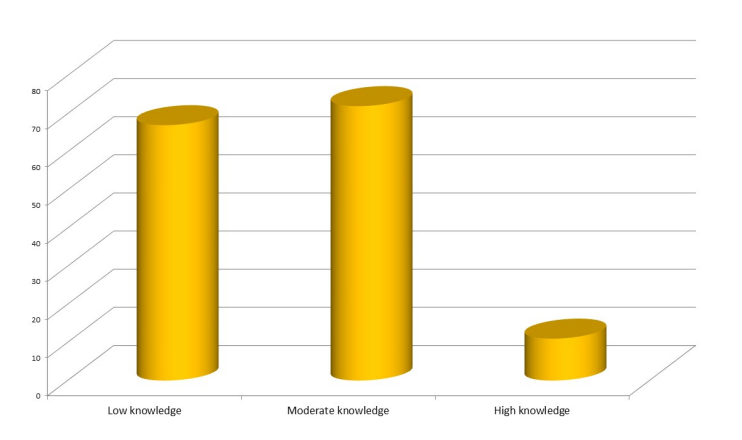

The practice of Post C-Section self-care among Postpartum Women.

To find out the practice of PCS among postpartum women, the researcher asked post-partum 
women to report on their performance of Post CSection self-care.

Performance of Post C-Section self-care

The majority (78\%) of the participants reported having been performing Post C-Section self-care. Only a small percentage (22\%) of the participants reported not to have been performing Post C-Section self-care as shown in the figure below.

Figure 5: Performance of Post C-Section selfcare

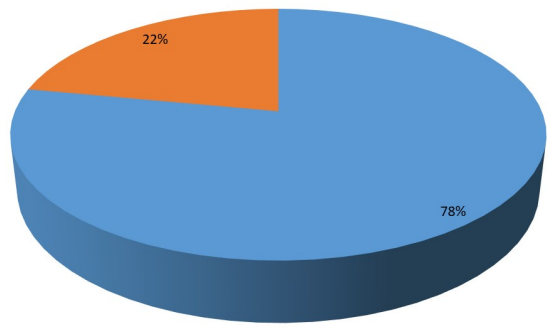

\section{How important is it to perform Post C- Section self-care?}

The majority $58 \%(87)$ reported that Post CSection self-care is very important, $24.7 \%$ ( 37 ) somewhat important, $17.3 \%$ (26) extremely important and none reported that Post C-Section self-care is not important as shown in the table below.

\section{Different Post C-Section self-care practices}

The majority of the Post C-Section self-care practice reported was good hygiene with a frequency of 94 , followed by the exercise of 56 , nutrition of frequency 31 and pain management of frequency 12. No participant reported no sexual activity as a Post C-Section self-care practice as shown in the figure below.

Figure 6: Frequencies of the participant's PCS

\section{Practices}

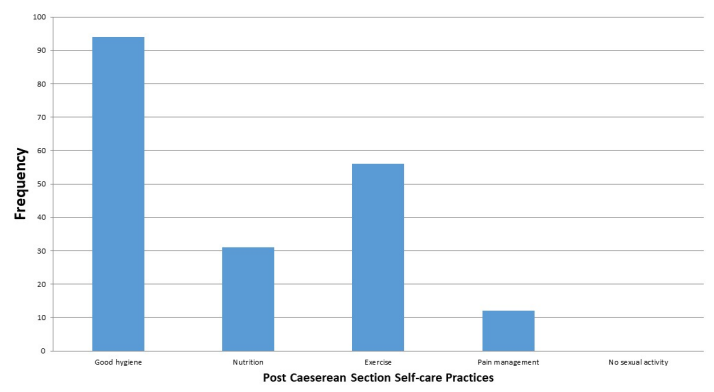

Pain management practices
The majority of the participants who manage pain reported managing pain using pharmacological measures $(n=107) 71 \%$ while only $(n=43) 29 \%$ of the participants reported managing pain non pharmacologically

Figure 7: Pain management practices of the participants

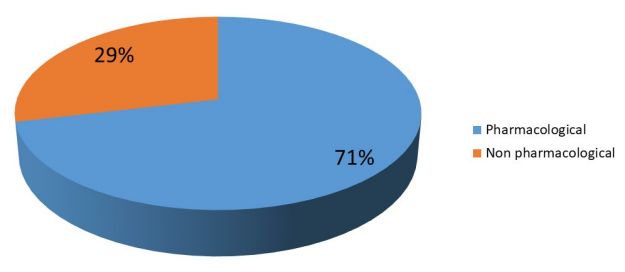

\section{DISCUSSION}

Demographic characteristics of the postpartum women participants.

Analysis of participants by age showed that the majority $46.7 \%$ are in the age range of 25 years and above, still, the majority of the participants 39.3\% were Gravida 2s. There's no significant correlation between age, parity, and C-section according to (Dabbas et al., (2007) who found out that indications for CS showed no significant difference between the different age and parity subgroups.

Banyankore were the majority tribe (73.3\%) found in the study and this could simply be because they are the predominant ethnic group in the region.

There is no significant effect of religion on PCS but religious gatherings could provide a platform for mass education about health promotion programs, PCS inclusive.

Knowledge of postpartum women about Post cesarean self-care

The findings of this study indicated that regarding knowledge about PCS, postpartum women are less informed as only $40 \%$ of them have ever heard about PCS. A search of the literature does not reveal any Ugandan study on postpartum women for comparison.

The findings of this study about the knowledge of good hygiene revealed that only $28.7 \%$ of the postpartum women talked about good hygiene as a form of Post Cesarean self-care. This is in line with 
Table 6. How important to perform Post C-Section self-care

\begin{tabular}{lll}
\hline & Frequency & Percentage \\
Extremely important & 26 & 17.3 \\
Not important & 0 & 0 \\
Somewhat important & 37 & 24.7 \\
Very important & 87 & 58 \\
\hline Total & 150 & 100.0 \\
\hline
\end{tabular}

a study by Missirya., (2016) in India on knowledge of personnel hygiene which revealed over $70 \%$ of women having inadequate knowledge and none had adequate knowledge and this could have been attributed to the fact that data was collected from a low resource setting facility with most of the clients having limited medical personnel for patient health education.

The findings of this study about the knowledge on post-natal exercises revealed that $21.3 \%$ of the postpartum women talked about Post-natal exercises as a form of Post Cesarean self-care. This in line with a study by Mbombil (2017) in South Africa regarding knowledge of different post-natal exercises that revealed $72 \%$ didn't perform the exercises because they simply lacked knowledge on what to do and in contrast with another study in Nigeria by Adeniyi, et al., (2013) where $60.0 \%$ of the participants knew that postpartum exercises were important for their postpartum health though this study was typical to Post Cesarean alone.

The findings of the current study reveal that no participant talked about not having sexual activity after CS as a form of Post Cesarean section selfcare yet the study done by Lisa, et.al., (2007) in the US showed that only $11 \%$ of the participating mothers and $17 \%$ of the participating fathers had one or no concern about postpartum sexuality.

This study revealed that no postpartum woman was fully aware of all the aspects of PCS and only $26 \%$ could talk of more than 2 aspects of the PCS and therefore postpartum women were less informed about PCS. These findings of low knowledge about episiotomy self-care are not surprising, given that a similar low level of awareness has been reported in several studies such as a study in Nigeria that revealed poor knowledge of episiotomy self-care among post-natal women (Probandari et al., (2017); Harpreet et al., 2019).
The low knowledge may also be that the health workers themselves do not instruct mothers about PCS and encourage them to undertake regular care as shown in this study whereby only 36 had received information about PCS from health workers. This view is reinforced by the report of the study on eight midwives in Alban Jodeen hospital Sudan where none of the midwives gave mothers any information about pain relief and over $90 \%$ of them didn't give any advice regarding the same. Health workers also need to not only use the hospital health education talks to deliver knowledge to mothers but also utilize communication channels like radios that are accessed by most of the participants in our local setting. This is due to the reason that very low participants were found to have received information about PCS via media platforms only 2 under the data analysis.

The implication of the low rating of the knowledge is attributable to the lack of health education on PCS. However, educating the women on PCS has a high potential to succeed as an important health promotion tool. As found out in the same study after an effective planned teaching program of mothers on PCS gave a very good knowledge rating 76-100 range

\section{The practice of PCS among postpartum women.}

The findings of the study revealed $22 \%$ (33) of the postpartum women don't perform PCS at all. This shows a low practice of PCS among postpartum women. The poor practice of PCS observed amongst the participants is as a result of low Knowledge of PCS in the aspect of hygiene, pain management, nutrition, delay of sexual activity, and exercise as all are recommended for all.

The findings of this study revealed that $(n=107)$ $71.3 \%$ of the mothers manage their pain using pharmacological measures compared to the first line advised none pharmacological measures. This 
study is in line with a study by Wuytack, (2016) on the effect of Anti-inflammatory drugs for relief of perineal pain after childbirth carried out on 4141 women in the experimental study, more who received a single dose of NSAID achieved more pain relief compared to those on the placebo after 4 hours. But WHO, 2018 recommends the use of Non-pharmacological as first-line pain management. This is supported by (Peter et al., 2006) who indicated that the choice of the analgesic to be used should be carefully made to minimize transfer in breast milk, to have little or no effect on neonates, and minimal maternal side effects. Nonpharmacological measures like walking can relieve pain rather than using drugs like using excessive sedative opioids as (Peter et al.,2006) says in the same study yet these women need to ambulate, to be alert and energetic enough to care for, interact with and breastfeed their newborn. Thus indicating the overall poor practice of PCS among the postnatal mother in the aspect of pain management

In terms of hygiene, this study revealed that $(n=94) 62.7 \%$ of the mothers reported to have been practicing personal hygiene but their practice wasn't good. This study is in line with the finding of Sahbanathul, (2016) where about 38(63.3\%) out of the 60 postnatal mothers had their practice of maintaining good personnel hygiene being poor. This turnout could be attributed to the fact that most women clean themselves with local prescribed local herbs that are contrary to what is taught by the medical personnel. Thus indicating the poor practice of PCS among the postnatal mother

The findings of this study revealed that only $(n=56) 37.3 \%$ of the mothers manage to practice exercise during their PCS. And these were only simple walking exercises. The finding of this study is in the line with another by Adeniyi et al., (2013) on postpartum exercises among Nigerian Women which revealed that 109 out of 229 women were not engaged in any exercise hence took longer to recover compared to those who exercised.

The findings of this study reveal that none of the participants practiced delay in sexual activity after CS. This is in contrast with the study by Cindy, et.al (2007) and the one by Kaewsarn et al., (2003) which both highlighted that in many cultures, sexual activity is avoided for a variable length of time, ranging from 20-100 days and often this practice is encouraged not only by the cultural community but also by medical practitioners to encourage appropriate healing following childbirth. This indicates that there is an overall poor practice of PCS among the postnatal mother in the aspect of delay in sexual activity.

\section{Conclusion}

Generally, in this study, the knowledge of postcesarean section self-care among postpartum women at MRRH in Mbarara was poor, suggesting that these postpartum women are unaware of the value of this personal health promotion tool.

And also the participation of mothers in postcesarean section self-care is very low. This was found to be highly linked with a lack of knowledge about Post cesarean section self-care implying that most mothers are not aware of the different practices available to address their concerns after delivery.

These practical factors must be considered, and relevant solutions identified so that Uganda can ensure its women and youngest citizens have the best hope for survival.

\section{Nursing implications}

\section{This could;}

Help nurses better package the post-cesarean self-care messages for women to better understand

Prompt the hospital to implement a well-defined organized post-cesarean section self-care program

Inform the ministry of health about the challenge which can respond through overcoming informational barriers by distributing educational materials, pamphlets and holding campaigns and workshops to increase the women's understanding of the need for post-cesarean section self-care

Inform policymakers and they realize they need to package health education sessions at all levels of maternal care in Uganda about cesarean section and its care.

Call for further research to find out knowledge and practices in different regions of Uganda and the need for health professionals to be incorporated in future research about post-cesarean section self-care.

Prompt health workers to reflect on the way they deliver services and how much knowledge they have regarding post-cesarean section self-care.

The overall outcome would be quality service delivery and improved maternal health. 


\section{Recommendations}

Based on the findings in the study, the researcher wishes to make the following recommendations.

\section{Hospital Administration}

Implement a well-defined organized postcesarean section self-care program

Conduct awareness sessions for mothers in both antenatal and postnatal units regarding self-care guidelines for women to enhance self-care knowledge \& practices among pregnant and postpartum women.

There should be encouragement and health education by health workers who are familiar with the proper technique of performing PCS. Such teaching could be incorporated into routine ANC interactions, especially for prime gravidas.

\section{Ministry of Health}

Overcome informational barriers by distributing educational materials, pamphlets and holding campaigns and workshops to increase the women's understanding of the need for post-cesarean section self-care while ensuring that messages reach those who make the decisions such as mothers-in-law, husbands, and the community.

The multidisciplinary approach among health workers including doctors, midwives, nurses, social workers, physiotherapists, and dieticians should be strengthened for a more efficient referral system.

Policymakers need to package health education sessions at all levels of maternal care in Uganda about cesarean section and its care.

\section{Further research}

Further research is recommended to find out knowledge and practices in different regions of Uganda and health professionals should also be incorporated in future research about post-cesarean section self-care.

\section{Limitations}

The restriction of the sample population to Southwestern Uganda limited knowledge and practices to a homogenous population that may not be generalized $d$ to the whole of Uganda. This should be considered in the future for more generalizable information.

Health professionals were also not included in the study and this did not give me conclusive reasons as to why most of the mothers lacked knowledge about post-cesarean section self-care. However, this is a stepping stone towards further re- search on post-cesarean self-care in Mbarara Regional Referral Hospital.

\section{ABBREVIATIONS AND ACRONYMS}

HBM Health Belief Model

MRRH Mbarara Regional Referral Hospital

MUST Mbarara University of Science and Technology

PG Prime Gravida

PCS Post cesarean section self-care

WHO World Health Organization.

\section{OPERATIONAL TERMS}

\section{Knowledge}

The level of awareness of participants about Post Cesarean section

Self-care within 42 days after delivery

Operative deliveries. An obstetric procedure in which active measures are taken to accomplish delivery.

\section{Post-Cesarean section complications}

Unpleasant conditions result when the Cesarean Section is not given proper care.

Post-Cesarean section self-care

Techniques that involve the post-partum women self-care once they have had a Cesarean section made on them for early recovery and prevention of any of its complications.

Practice

How postpartum women perform self-care after Cesarean section within 42 days after delivery.

\section{References}

1) Adeniyi, A., Ogwumike, O. \& Bamikefa, T., (2013) "Postpartum exercise among Nigerian women: issues relating to exercise performance and selfefficacy". ISRN obstetrics and gynecology. http s://doi.org/10.1155/2013/294518 PMid:23844290 PMCid:PMC3697309

2) Aiken, L., Consuelo, C., Simonetti, M., Lake E., Galian, A., Garbarini, A., Bravo, D.,Smith H. (2018) "hospital nurse staffing and patient outcomes." Revista Médica Clínica Las Condes 29, (3):322-327 htt ps://doi.org/10.1016/j.rmclc.2018.04.011

3) Cindy-Lee Dennis, Kenneth Fung, Sophie Grigoriadist, Gail Erlick Robinson, Sarah Romans, Lori Ross (2007), "traditional postpartum practices and rituals: a qualitative systematic review" women's health journal issue 1745-5065 https://doi.org/10.2 217/17455057.3.4.487 PMid:19804024

4) Dabbas M, A Al-Sumadi (2007), "Cesarean section rate: much room for reduction." Clinical and 
experimental Obstetrics and gynecology 34(3), 146148

5) Daftary SN., Chakravarthi S. (2011). Manual of Obstetrics. 1st Edition, Elsevier India (p) Ltd. Reed Elsevier India Pvt. Ltd.

6) Dennis, C., Grigoriadis, S., Robinson, G.E., Romans, S., Ross, L.,( 2007) "Traditional Postpartum Practices and Rituals". A qualitative systematic review, Women's Health, 3, 487-502. https://doi.org/1 0.2217/17455057.3.4.487 PMid:19804024

7) Djellouli, N., Mann, S., Nambiar, B., Meireles, P., Miranda, D., Barros, H., Bocoum, F. Y., Yaméogo, W. M. E, Yaméogo, $C$. \& Belemkoabga, $S,(2017)$ "Improving postpartum care delivery and uptake by implementing context-specific interventions in four countries in Africa: a realist evaluation of the Missed Opportunities in Maternal and Infant Health (MOMI) project" BMJ global health, 2, e000408. https://doi.org/10.1136/bmjgh-2017-00 0408 PMid:29225949 PMCid:PMC5717926

8) Duysburgh, E (2016) "Quality of maternal and infant care in sub-Saharan Africa: challenges and opportunities". Ghent University.

9) Duysburgh, E., Kerstens, B., Kouanda, S., Kaboré, C. P., Yugbare, D. B., Gichangi, P., Masache, G., Crahay, B., Sitefane, G. G. \& Osman, N. B.,( 2015) "Opportunities to improve postpartum care for mothers and infants: design of context-specific packages of postpartum interventions in rural districts in four sub-Saharan African countries". BMC pregnancy and childbirth, 15, 131. https://doi.org /10.1186/s12884-015-0562-8 PMid:26038100 PMCid:PMC4453099

10) Fok, D., Aris, I. M., Ho, J., Lim, S. B., Chua, M. C., Pang, W. W., Saw, S. M., Kwek, K., Godfrey, K. M. \& Kramer, M. S., (2016) "A comparison of practices during the confinement period among Chinese, Malay, and Indian Mothers in Singapore". Birth, 43, 247-254. https://doi.org/10.1111/birt.122 33 PMid:27018256 PMCid:PMC4992357

11) Hall, K (2018) "Post-partum rehabilitation: Supporting the wellbeing of the mother and child.

12) Harish M., Sehdev. (2019) Cesarean childbirth (C-Section) [online]emedicinehealth.Available at: w ww.emedicinehealth.com[Accessed 12 Sep 2019]

13) Harpreet K., Sarabjeet K., Neelam., Manisha R., (2019). Assessing the Knowledge Regarding Episiotomy Care among Primigravida Mothers. Journal of Perinatal, Pediatric and Neonatal Nursing. http:/ /doi.org/10.5281/zenodo.3242272
14) Harrison, $S$ and Goldenberg, R (2016) "maternal health, Neonatology, and Perinatology", 2:6 pages 1-10 https://doi.org/10.1186/s40748-016-00 33-x PMid:27398224 PMCid:PMC4937522

15) Kamaria, K., Long, C. \& Nurhanisah, S.,(2015) "Traditional Malay massage as an alternative treatment approaches in rehabilitation". a narrative review the state of evidence. Physiotherapy, 101, e706. https://doi.org/10.1016/j.physio.2015.03.35 58

16) Lim L. (2011) "For Chinese moms, birth means 30 days in pijamas". Culture and traditions, 1-7.

17) Lisa P., Owens A., \& Raymond C (2007), "postpartum sexuality concerns among first time parents from one US academic hospital", the journal of sexual medicine volume 4, issue 1 pages 115 $123 \mathrm{https}: / /$ doi.org/10.1111/j.1743-6109.2006.003 79.x PMid:17087807

18) Mbombi, M., Thopola, M., \& Kgole, J. (2017). Puerperas' knowledge regarding postpartum exercises in a tertiary hospital in the Capricorn District of Limpopo Province, South Africa. South African Journal Of Obstetrics And Gynaecology, 23(1), 3-6. doi:10.7196/SAJOG.2017.v23i1.1059 https://doi.or g/10.7196/SAJOG.2017.v23i1.1059

19) Michaeleen, $D$ (2018) "Rate of C-sections is rising at an 'alarming' rate". [online] Available at: $w$ ww.npr.org[Accessed 12 Sep 2019]

20) Nankwanga, A., \& Phillips, J.,(2008) "Factors influencing utilisation of postnatal services in Kampala, Uganda".

21) Ngonzi J., Kabakyenga J., Peter Kivunike Mukasa (2016) " puerperal sepsis, the leading cause of maternal deaths at a tertiary university Teaching hospital in Uganda". BMC pregnancy and childbirth 16:207 https://doi.org/10.1186/s12884-016-0986-9 PMid:27495904 PMCid:PMC4974713

22) Pattaya K., Wendy M., Debra C. (2003). Traditional postpartum practices among Thai women. JAN Volume41, Issue4 Pages 358-366

https://doi.org/10.1046/j.1365-2648.2003.02534 .x PMid:12581101

23) Peter H, Pan (2006), "post cesarean delivery pain management: multimodal approach", international journal of Obstetric Anesthesia, volume15, issue 3 pages 185-188 https://doi.org/10.1016/j.ijo a.2006.04.004 PMid:16798441

24) Probandari, A., Arcita, A., Kothijah, K. (2017). Barriers to utilization of postnatal care at village level in Klaten district, central Java Province, Indonesia. BMC Health Serv Res 17, 541 (2017). https://do 
i.org/10.1186/s12913-017-2490-y PMid:28784169 PMCid:PMC5547562

25) Rani Vijaya M, Maryam Ghanbari Andarieh, Fatemeh Hoseinpoor Heidary, (2016) "Effectiveness of planned teaching programme on practice of post natal exercises among mothers who have undergone lower segment cesarean section." International Journal of Reproduction, Contraception, Obstetrics and Gynecology 5(11):3782-3788 https://do i.org/10.18203/2320-1770.ijrcog20163839

26) Rojamma M. (2010) "Teaching third Trimester Pregnant Women about New Born Care." the Indian Journal of Nursing and Midwifery, 2(2):3656

27) Rudman, A., Waldenström, U. (2007) "Critical views on postpartum care expressed by new mothers." Biomed Central the open access publisher 7: 178. https://doi.org/10.1186/1472-6963-7-178 PMid:17983479 PMCid:PMC2216017

28) Sahbanathul, M. (2016) "Knowledge and Practice of Postnatal Mothers Regarding Personal Hygiene and Newborn Care" International Journal of Pharmaceutical Sciences Review and Research 40(1):89-93

29) Wloch $C$, Wilson J, Lamagni T, Harrington $P$, Charlett A, Sheridan E.(2012) "Risk factors for surgical site infection following caesarean section in England." An International Journal of Obstetrics and Gynaecology BJOG ;119:1324-1333. https://doi.org/ 10.1111/j.1471-0528.2012.03452.x PMid:22857605

30) Wuytack F, Valerie S, Brian J (2016), "Oral non-steroidal anti-inflammatory drugs (single dose) for perineal pain in the early postpartum period" cochrane database of systematic reviews https://doi.org/10.1002/14651858.CD01135 2.pub2 PMid:27412362 PMCid:PMC6461153

31) Zawn, V (2018). How to speed up recovery from a cesarean delivery [online]medicalnewstoday. Available at: www.m edicalnewstoday.com[Accessed 13 Sep 2019. 